\title{
Pain Relief Salvage with a Novel Minimally Invasive Posterior Sacroiliac Joint Fusion Device in Patients with Previously Implanted Pain Devices and Therapies
}

\author{
Timothy R Deer (D) \\ Adam Rupp ${ }^{2}$ \\ Ryan Budwany ${ }^{3}$ \\ Christopher J Bovinet ${ }^{4}$ \\ John W Chatas ${ }^{5}$ \\ Stephen T Pyles ${ }^{6}$ \\ Nomen Azeem (iD) \\ Sean $\operatorname{Li}\left(\mathbb{D}^{8}\right.$ \\ Ramana Naidu (1D) \\ Ajay Antony ${ }^{10}$ \\ Jonathan M Hagedorn (iD) ${ }^{11}$ \\ Dawood Sayed (ID ${ }^{12}$ \\ 'The Spine \& Nerve Centers of the \\ Virginias, Charleston, WV, USA; \\ ${ }^{2}$ Department of Physical Medicine and \\ Rehabilitation, University of Kansas \\ Medical Center, Kansas City, KS, USA; \\ ${ }^{3}$ West Virginia University, Charleston, \\ WV, USA; ${ }^{4}$ The Spine Center of \\ Southeast Georgia, Brunswick, GA, USA; \\ ${ }^{5}$ Michigan Pain Specialists, Ypsilanti, MI, \\ USA; ${ }^{6}$ Pain Treatment Centers, Ocala, FL, \\ USA; ${ }^{7}$ Florida Spine \& Pain Specialists, \\ Riverview, FL, USA; ${ }^{8}$ Premier Pain \\ Centers, Shrewsbury, NJ, USA; \\ ${ }^{9}$ California Orthopedics \& Spine, \\ Larkspur, CA, USA; ${ }^{10}$ The Orthopaedic \\ Institute, Gainesville, FL, USA; \\ "Department of Anesthesiology and \\ Perioperative Medicine, Division of Pain \\ Medicine, Mayo Clinic, Rochester, MN, \\ USA; ${ }^{2}$ Department of Anesthesiology, \\ University of Kansas Medical Center, \\ Kansas City, KS, USA
}

Correspondence: Timothy R Deer The Spine \& Nerve Centers of the Virginias, Charleston, WV, 2530I, USA

Tel + I 304-347-6/20

Email doctdeer@aol.com
Background: Sacroiliac joint (SIJ) pain is a common cause of low back pain, a problem experienced by two-thirds of adults in the United States population. Traditionally, the management of persistent SIJ-related pain has involved conservative therapies (physical therapy, topical medications, oral anti-inflammatory medications), interventional therapies (SIJ steroid injections or ablation), and surgery (SIJ fusion; open and lateral approach). Recent advancements in technology have paved the way for SIJ fusion via a posterior approach, which aims to minimize complications and enhance recovery.

Objective: The purpose of this study is to introduce the concept of the posterior approach to SIJ fusion as a feasible adjunct and salvage technique for patients with inadequate pain relief from other minimally invasive surgical procedures, and to validate its efficacy through a retrospective multicenter data analysis.

Design: Multicenter retrospective observational study.

Methods: Patients with refractory SIJ pain were treated by interventional pain physicians at one of the eight different pain management centers. All patients underwent posterior SIJ fusion via the $\mathrm{LinQ}^{\mathrm{TM}}$ sacroiliac fusion procedure. Demographical data were collected, in addition to patient-reported pain relief.

Results: A total of 111 patients were included in the study and underwent posterior SIJ fusion for refractory SIJ-related pain following the use of spinal cord stimulation (SCS), interspinous spacer (ISS), intrathecal drug delivery (IDDS), and/or minimally invasive lumbar decompression (MILD). Overall, the mean patient reported pain relief following posterior SIJ fusion was $67.6 \%$. In patients with a history of failed back surgery syndrome, the mean patient reported pain relief was $76.5 \%$.

Conclusion: In this retrospective case series of patients with continued intolerable pain following SCS, ISS, IDDS, or MILD, a novel posterior SIJ fusion device provided significant pain relief in a salvage manner. These early results suggest that this intervention may be a therapeutic option to consider in these patients.

Keywords: sacroiliac joint pain, posterior SIJ fusion, salvage, spinal cord stimulation, lumbar decompression

\section{Introduction}

Sacroiliac joint (SIJ) disease is a common but often underdiagnosed source of chronic pain. Estimates range from $10 \%$ to $60 \%$ (depending on diagnostic criteria) of the population will suffer from primary SIJ dysfunction at some point during their life. ${ }^{1}$ More likely, however, it is a concurrent low back pain (LBP) pathology with an SIJ component. An estimated $70-85 \%$ of the population will experience 
LBP at some point during their lifetime and $15-30 \%$ of these patients will have associated SIJ pain. ${ }^{2,3}$ This underdiagnosis originates from the complexity of the joint along with the difficult diagnostic nature of SIJ-related pathology and its overlapping symptomatology with other painful conditions.

Multiple chronic pain pathological conditions may share a similar pain pattern as the SIJ, including lumbar spine degeneration and adjacent segment disease following lumbar spinal fusion. An estimated $40-43 \%$ of lumbar fusion patients will develop SIJ pain within 12 months after fusion surgery. ${ }^{4,5}$ This is in addition to the $75 \%$ of the patients showing signs of degeneration on CT at 5 years post-op. ${ }^{6}$ Other studies place the post-op incidence of sacroiliitis from $5 \%$ to $75 \%$ stating it is directly proportional to the number of fused segments. ${ }^{7,8}$

Given the concomitant nature of pain associated with the SIJ and other related conditions, pain physicians can expect to treat patients with overlapping symptoms. Unfortunately, the treatment of one pathology may not relieve the pain associated with the other. Subsequently, proven therapies for lumbar spinal stenosis (ie interspinous spacers [ISS], minimally invasive lumbar decompression [MILD]) and failed back surgery syndrome (FBSS)/persistent spinal pain syndrome (ie spinal cord stimulation [SCS], intrathecal drug delivery systems [IDDS]) may not deliver satisfactory pain relief. In those instances, proper diagnosis and treatment of SIJ pathology must be considered.

An accurate diagnosis of SIJ pain can be challenging. However, utilizing a standardized approach to the diagnosis of SIJ pain is helpful and should include the following areas: subjective experience, physical exam, diagnostic tests, and response to diagnostic blocks. ${ }^{9,10}$ Following appropriate diagnosis, treatment for SIJ pain starts with conservative measures including physical therapy, medications, and injections, which may then progress to more invasive options, such as radiofrequency ablation, if pain control is not achieved. ${ }^{11,12}$

If long-term pain relief is not achieved with initial interventions and treatments, then it is reasonable to consider SIJ fusion. SIJ stabilization aims to reinforce joint/ ligamentous laxity and reduce further inflammation and degeneration. Pain relief is likely mediated by SIJ stabilization, reducing ligamentous strain and easing load transfers. $^{13}$ Minimally invasive (MIV) procedures have grown in popularity since 2008 and have mostly replaced open surgical fusions (OSF). ${ }^{14-18}$ This is due to improved outcomes, reduced recovery times, higher union rates (OSF has non-union rates of 9-41\%), and reduced risk of serious complications (OSF complication rates of 30\% compared to $13.7 \%$ for MIV). ${ }^{19-21}$ MIV SIJ fusion can be performed using two approaches: lateral or posterior. The lateral approach was first developed in 2008 and has been supported by peer-reviewed publications and numerous trials. However, recent advancements in the field of minimally invasive surgery paved the way for less invasive posterior fusion. This posterior fusion approach aims to reduce neurological complications by avoiding the sacral foramen, passes through and manipulating less soft tissue, avoiding nervous and arterial structures and decreasing post-op recovery time. Unlike the lateral approach which typically requires patients to undergo general anesthesia, the posterior approach can be performed under conscious sedation with local anesthetic and is typically an outpatient day surgery procedure. ${ }^{22}$ The procedure is less invasive than previous methods.

The goal of this study is to introduce the concept of the posterior approach to SIJ fusion as a feasible adjunct and salvage technique for patients with inadequate pain relief from other minimally invasive surgical procedures, and to validate its efficacy through a retrospective multicenter data analysis.

\section{Methods}

\section{Study Design}

This study was a retrospective review of eight different pain management centers to determine the role of SIJ fusion via a posterior approach in treating those patients who have undergone other invasive pain treatment therapies and have coexisting SIJ dysfunction. An IRB waiver was granted by WCG IRB to the primary investigator who provided oversight of this study (IRB \#1-1464876-1). All patient data collected were de-identified and kept confidential in compliance with the Declaration of Helsinki. The process for data mining was reviewed and approved by the legal entities at the local institutions.

\section{Data Collection}

Demographical data, in addition to pre-procedural and post-procedural patient reported pain relief (\%) was collected by each individual site and entered into a secure database created by the corresponding author to maintain confidentiality. All patient data was anonymized. The guidelines in the Declaration of Helsinki were followed. The study included a total of 111 patients who reported incomplete pain resolution from an initial interventional 
spine therapy (ISS, SCS, IDDS, and/or MILD), were diagnosed with SIJ pathology, and underwent a novel minimally invasive SIJ posterior stabilization procedure. All patients were at least three-month post-implantation of the SIJ fusion device. Data were extracted from the medical record and included age, sex, BMI, history of prior lumbar spine surgery, prior advanced interventional pain procedures, date of SIJ fusion, and date of last follow-up.

\section{Inclusion Criteria}

Patients who were included in this study met all preimplant evaluation criteria as described: pain was primarily non-radicular, described in the lower back primarily below the belt line, they were positive for at least 3/ 5 provocative exam maneuvers for SIJ dysfunction (distraction, thigh thrust, FABER, compression, and Gaenslen's), and obtained a $>50 \%$ reduction in pain after an image guided diagnostic SIJ injection with local anesthetic. Selected patients who then failed at least 6 months of conservative treatments (physical therapy, medications and injections) were considered for more advanced interventional therapies, such as ISS, SCS, IDDS, and MILD.

\section{Implant Procedure}

The procedure was performed based on the technique described for the $\operatorname{LinQ}^{\mathrm{TM}}$ SIJ stabilization system
(PainTEQ, Tampa, FL, USA). With the patient in a prone position, a 22-gauge needle is inserted into the SIJ for lidocaine administration. A stab incision is made, and the guide pin is advanced into the joint (Figure 1). From the lateral fluoroscopic view, the guide pin is advanced to the anterior cortical line. A larger incision is made to accommodate the external dilator. In the oblique fluoroscopic view, the dilator and internal retraction guide are advanced over the guide pin until seated within the SIJ. This is confirmed in a lateral view (Figure 2). The internal dilator is removed, and the decorticator is placed into the outer dilator. The decorticator is seated in the joint with a mallet and then removed using the reverse slap hammer technique (Figure 3). The implant graft site is filled with a demineralized bone matrix (DBM) putty, and the implant is tapped into place (Figure 4). Final fluoroscopic images are obtained (Figure 5). Hemostasis is achieved, and irrigation of the incision is performed. Deep closure typically consists of 2-0 Vicryl sutures, while superficial skin closure is physician dependent. A sterile bio-occlusive dressing is applied to the incision site.

\section{Statistical Analysis}

A univariate statistical analysis was performed to report the outcomes. Results were reported as mean and standard deviations for continuous outcomes, and frequency (\%) for

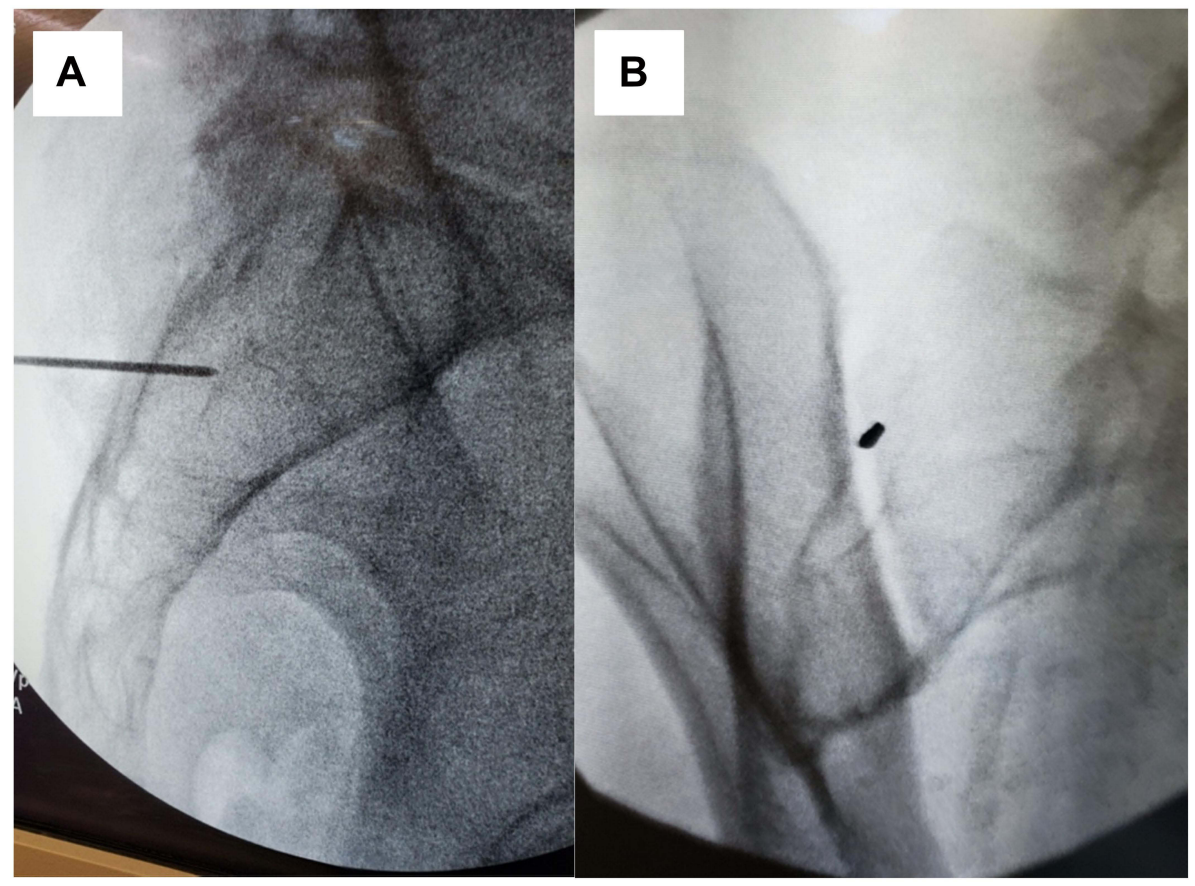

Figure I Lateral (A) and anteroposterior (B) fluoroscopic images showing guide pin insertion into the sacroiliac joint. 


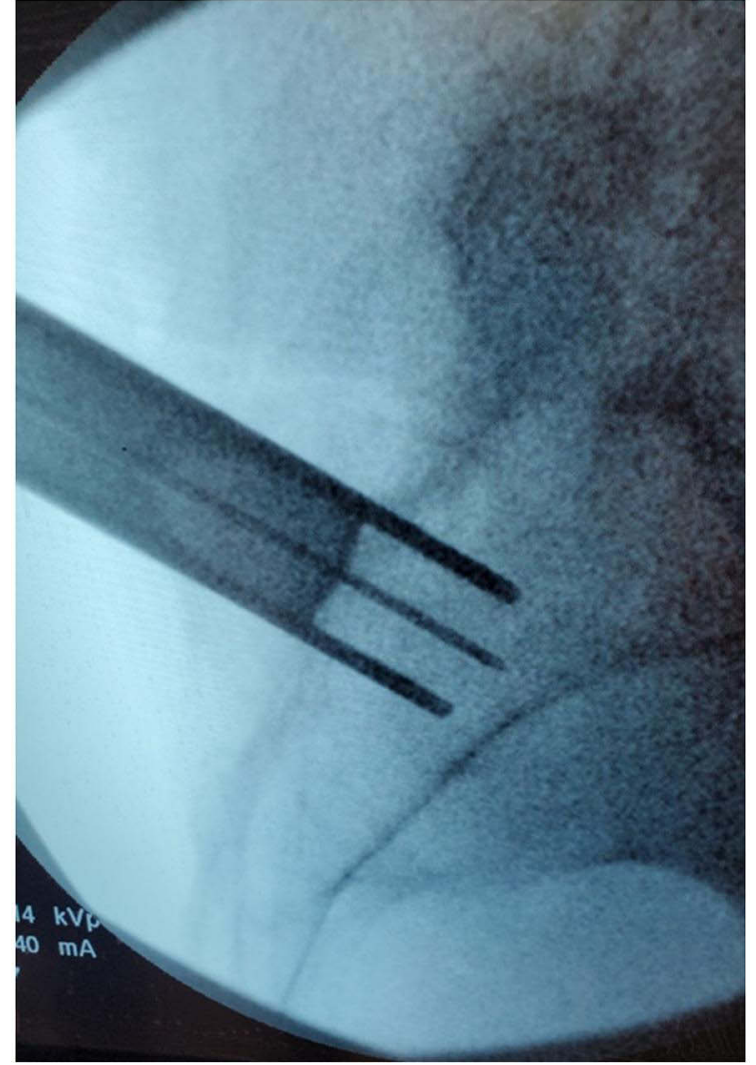

Figure 2 Lateral image showing the dilator and internal retraction guide placed over the guide pin and seated within the sacroiliac joint.

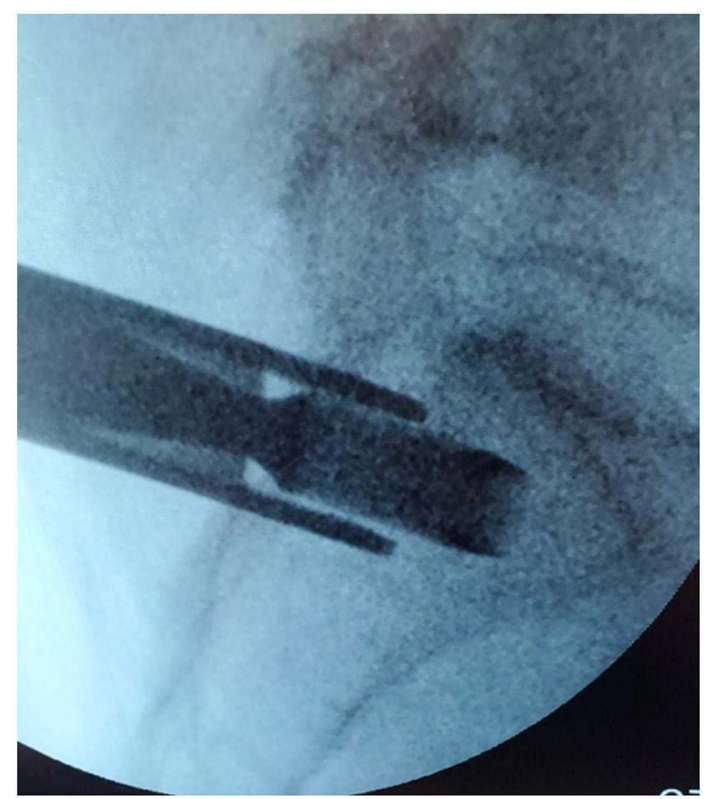

Figure 3 Lateral image showing the decorticator placed within the sacroiliac joint.

categorical outcomes. All analyses were performed using SPSS (IBM SPSS Statistics for Windows, Version 21.0; Armonk, NY: IBM Corp.).

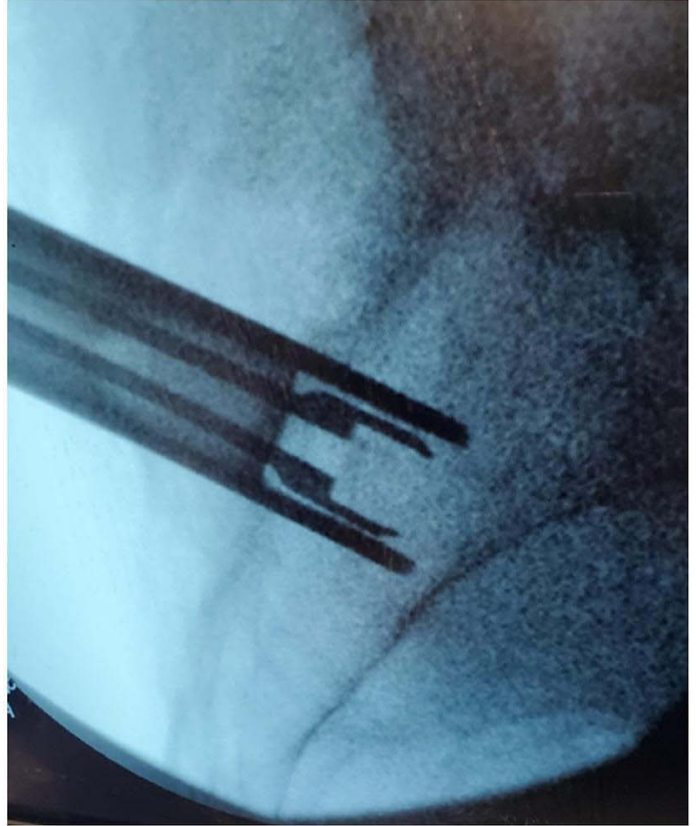

Figure 4 Lateral image showing the implant being inserted into the sacroiliac joint.

\section{Results}

A total of 111 patients were included in this retrospective review. Demographical data is shown in Table 1. The mean age was $69.8 \pm 9$ years. Sixty patients were female (54.1\%). The mean BMI was $30.6 \pm 6.2$. The overall totals for each of the prior procedures included 76 SCS (68.5\%), 39 ISS (35.1\%), 3 IDDS (2.7\%), and 2 MILD (1.8\%). Most patients had one prior interventional procedure; however, 9 patients $(8.1 \%)$ did have multiple prior procedures (7 patients had SCS+ISS, 2 patients had SCS+IDDS).

The mean time between SIJ fusion and the last followup was $290.9 \pm 195.7$ days. At the last follow-up, the mean overall patient reported pain relief was $67.6 \% \pm 28.9 \%$. One hundred and two patients (91.9\%) reported pain relief post-operatively of $\geq 30 \%$. Fifty-two patients $(46.8 \%)$ had a patient reported pain relief of $\geq 80 \%$ (Table 2 ).

In patients with a past medical history of FBSS, the mean time between SIJ fusion and the last follow-up was $349.4 \pm 233.4$ days. At the last follow-up, the mean overall patient reported pain relief was $76.5 \% \pm 25.5 \%$. Forty-nine patients $(96.1 \%)$ reported pain relief post-operatively of $\geq 30 \%$. Thirty patients $(58.8 \%)$ had a patient reported pain relief of $\geq 80 \%$ (Table 3 ).

\section{Discussion}

Given the significant number of patients with SIJ pain, there is an appropriate urgency within the chronic pain 


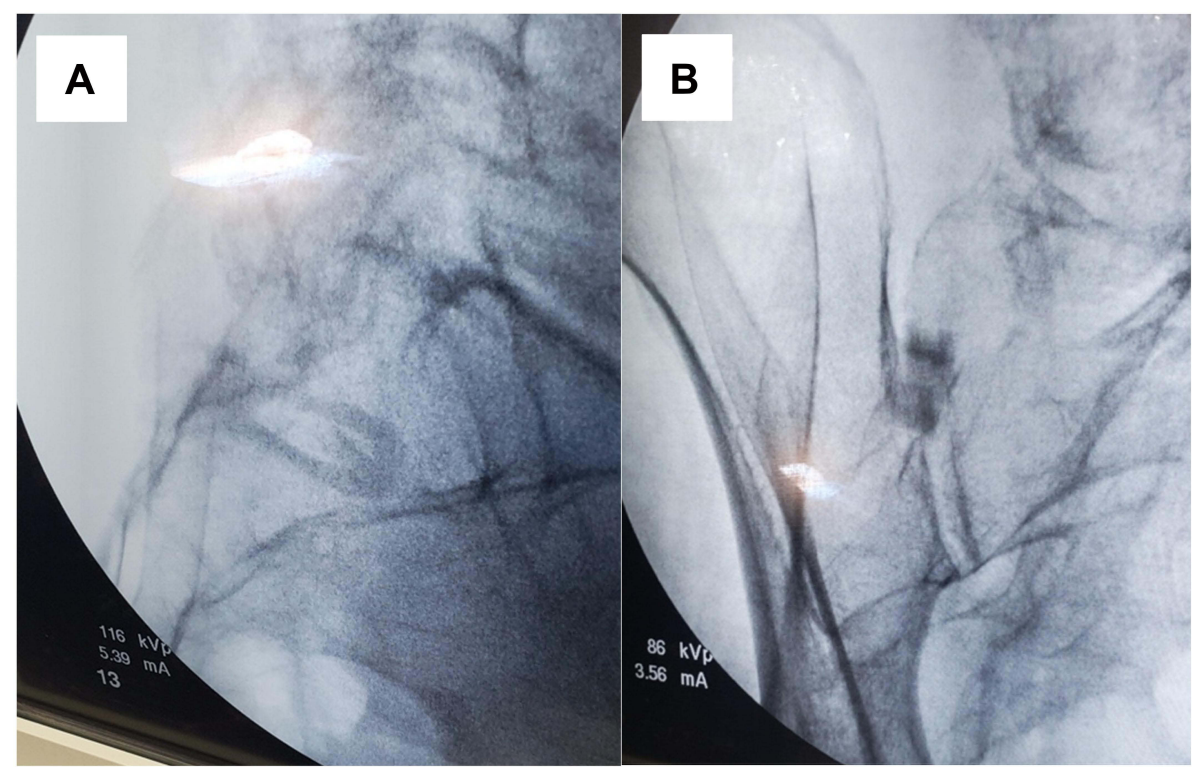

Figure 5 Lateral (A) and anteroposterior (B) fluoroscopic images showing the implant seated within the sacroiliac joint.

community to find a viable, long-term solution for these individuals. In recent years, there have been significant technological advancements in the SIJ fusion space,

Table I Baseline Clinical and Demographic Variables of Included Patients

\begin{tabular}{|l|c|}
\hline Variable & $\begin{array}{c}\text { Mean士SD or } \\
\text { n (\%) }\end{array}$ \\
\hline Age (years) & $69.8 \pm 9$ \\
\hline Sex, Female & $60(54.1 \%)$ \\
Sex, Male & $51(45.9 \%)$ \\
\hline BMI (kg/m $\left.{ }^{2}\right)$ & $30.6 \pm 6.2$ \\
\hline History of Failed Back Surgery Syndrome & $51(45.9 \%)$ \\
\hline Past Procedural History & \\
Spinal Cord Stimulator & $76(68.5 \%)$ \\
Interspinous Spacer & $39(35.1 \%)$ \\
Intrathecal Pump & $2(2.7 \%)$ \\
Minimally Invasive Lumbar Decompression & $290.9 \pm 195.7$ \\
\hline Mean follow-up time between SIJ fusion and last & \\
follow-up (days) & $29.8 \%$ \\
\hline
\end{tabular}

Table 2 Clinical Outcomes Following Sacroiliac Joint Fusion

\begin{tabular}{|l|c|}
\hline Patient Reported Pain Relief (\%) & Mean \pm SD or n (\%) \\
\hline Overall mean ( $\mathrm{n}=\mathrm{III})$ & $67.6 \% \pm 28.9 \%$ \\
Greater than or equal to $30 \%$ & $102(91.9 \%)$ \\
Greater than or equal to $50 \%$ & $92(82.9 \%)$ \\
Greater than or equal to $80 \%$ & $52(46.8 \%)$ \\
\hline
\end{tabular}

including the development of posterior SIJ fusion devices. However, there is a lack of data regarding the efficacy of this novel technique. In this retrospective multicenter case series, there was an overall decrease in pain across the entire patient cohort and a significant number of patients experienced profound pain relief. Considering these patients had undergone other advanced interventional pain techniques and had not experienced tolerable pain relief, these results are even more impressive.

The diagnosis of SIJ pain is difficult; identifying the pain generator is key to determining which intervention will optimize the patient's function. Unfortunately, lumbar spinal pathology and SIJ pain have many overlapping symptoms and thus present a significant challenge in determining specific treatment. Because of this, it is not surprising that many patients we may consider for SIJ fusion will have undergone other interventional pain procedures. In our patient cohort, all patients had undergone either SCS, ISS, IDDS, or MILD, and a select few had been treated with multiple advanced techniques. In the entire cohort,

Table 3 Clinical Outcomes Following Sacroiliac Joint Fusion in Patients with FBSS

\begin{tabular}{|l|c|}
\hline Patient Reported Pain Relief (\%) & Mean \pm SD or n (\%) \\
\hline Overall mean ( $\mathrm{n}=5 \mathrm{I}$ ) & $76.5 \% \pm 25.5 \%$ \\
Greater than or equal to 30\% & $49(96.1 \%)$ \\
Greater than or equal to $50 \%$ & $47(92.2 \%)$ \\
Greater than or equal to $80 \%$ & $30(58.8 \%)$ \\
\hline
\end{tabular}


patients reported a $68 \%$ mean improvement in pain over an average time period of 291 days. In patients with a diagnosis of failed back surgery syndrome, a group of patients we would expect to have higher rates of SIJ dysfunction, the results were even greater. In this cohort, the mean patient reported pain relief was $77 \%$ with an average follow-up time of approximately 1 year (349 days), and nearly $60 \%$ of patients had $\geq 80 \%$ pain relief. Our results suggest that SIJ pain overlay is very common in our chronic pain patients, and salvage of pain relief for other advanced techniques with SIJ fusion should be considered in those instances when patients are not obtaining the relief they desire.

Our manuscript does have weaknesses that should be mentioned. First, the study is a retrospective review and is limited by the inherent weaknesses of this study design, including the lack of a control group. Also, while some patients were followed for more than a year, the mean follow-up time period was less than twelve months. However, our data is encouraging, and demonstrates the need for controlled studies across multiple centers with larger patient groups to evaluate which post-salvage device candidate is best suited for this procedure. Lastly, we did not include health-related quality of life outcome measures, and this would be an important area of study in future publications.

\section{Conclusion}

In this retrospective case series of patients with continued intolerable pain following SCS, ISS, IDDS, or MILD, a novel posterior SIJ fusion device provided significant pain relief in a salvage manner. These early results suggest this intervention may be a therapeutic option to consider in these patients.

\section{Funding}

There is no funding to report.

\section{Disclosure}

Dr Timothy R Deer reports consultant fees from Cornerloc and PainTeq, outside the submitted work. Dr Christopher $\mathrm{J}$ Bovinet reports fees for teaching and lab training from PainTEQ, outside the submitted work. Dr John W Chatas reports personal fees from Gus Health and Painteq, during the conduct of the study; personal fees from Boston Scientific, outside the submitted work. Dr Nomen Azeem reports personal fees from and serves in the Physicians Advisory Board for Painteq, outside the submitted work. Dr Sean Li reports research grant and/or consultant from
PainTeq, Avanos, Boston Scientific, Nalu, Biotronik, Nevro, SPR Therapeutic, Avertitas Pharm, Saluda, Abbott, and Vertos, outside the submitted work. Dr Ramana Naidu is a shareholder for PainTeq and a consultant for Omnia Medical. Dr Ajay Antony reports grants, personal fees, and/ or non-financial support for consulting from Abbott, Boston Scientific, PainTeq, Vertos, Nalu, and SPR, outside the submitted work. Dr Jonathan M Hagedorn reports personal fees for consulting from and serving in the advisory board for Abbott, Boston Scientific, Nevro, and Speranza Therapeutics, outside the submitted work. Dr Dawood Sayed reports personal fees and owned stock from PainTeq, during the conduct of the study; personal fees from Abbott, Medtronic, Nevro, and Vertos, outside the submitted work. He also owned stock options from Vertos. The authors report no other conflicts of interest in this work.

\section{References}

1. Kibsgård TJ, Røise $\mathrm{O}$, Sturesson B, et al. Radiostereometric analysis of movement in the sacroiliac joint during a single-leg stance in patients with long-lasting pelvic girdle pain. Clin Biomech. 2014;29 (4):406-411.

2. Cohen SP, Chen Y, Neufeld NJ. Sacroiliac joint pain: a comprehensive review of epidemiology, diagnosis and treatment. Expert Rev Neurother. 2013;13(1):99-116.

3. Andersson GB. Epidemiological features of chronic low-back pain. Lancet. 1999;354(9178):581-585.

4. Liliang PC, Lu K, Liang CL, Tsai YD, Wang KW, Chen HJ. Sacroiliac joint pain after lumbar and lumbosacral fusion: findings using dual sacroiliac joint blocks. Pain Med. 2011;12(4):565-570.

5. Ha KY, Lee JS, Kim KW. Degeneration of sacroiliac joint after instrumented lumbar or lumbosacral fusion: a prospective cohort study over five-year follow-up. Spine. 2008;33(11):1192-1198.

6. DePalma MJ, Ketchum JM, Saullo TR. Etiology of chronic low back pain in patients having undergone lumbar fusion. Pain Med. 2011;12 (5):732-739.

7. Colò G, Cavagnaro L, Alessio-Mazzola M, et al. Incidence, diagnosis and management of sacroiliitis after spinal surgery: a systematic review of the literature. Musculoskelet Surg. 2020;104(2):111-123.

8. Anandjiwala J, Seo JY, Ha KY, Oh IS, Shin DC. Adjacent segment degeneration after instrumented posterolateral lumbar fusion: a prospective cohort study with a minimum five-year follow-up. Eur Spine J. 2011;20(11):1951-1960.

9. Lorio MP. ISASS policy 2016 update - minimally invasive sacroiliac joint fusion. Int J Spine Surg. 2016;10:26.

10. Maigne JY, Aivaliklis A, Pfefer F. Results of sacroiliac joint double block and value of sacroiliac pain provocation tests in 54 patients with low back pain. Spine. 1996;21(16):1889-1892.

11. AIM Specialty Health. Musculoskeletal program clinical appropriateness guidelines: sacroiliac joint fusion; 2017. Available from: https:// aimspecialtyhealth.com/guidelines/PDFs/2018/Ju101/AIM_ Guidelines_MSK_Sacroiliac-Joint-Fusion.pdf. Accessed June 5, 2021.

12. Laslett M. Evidence-based diagnosis and treatment of the painful sacroiliac joint. J Man Manip Ther. 2008;16(3):142-152.

13. Whang P, Cher D, Polly D, et al. Sacroiliac joint fusion using triangular titanium implants vs. Non-surgical management: six-month outcomes from a prospective randomized controlled trial. Int J Spine Surg. 2015;9:6. 
14. Chuang CW, Hung SK, Pan PT, Kao MC. Diagnosis and interventional pain management options for sacroiliac joint pain. Ci Ji Yi Xue Za Zhi. 2019;31(4):207-210.

15. Streitberger K, Müller T, Eichenberger U, Trelle S, Curatolo M. Factors determining the success of radiofrequency denervation in lumbar facet joint pain: a prospective study. Eur Spine J. 2011;20(12):2160-2165.

16. Yadav A, Hagedorn JM, D’Souza RS, Engle AM, Deer TR. Effect of Patient Characteristics on Reported Outcomes over 12 Months Following Lumbar Radiofrequency Ablation: a Retrospective Review of 500 Patients. Pain Pract. 2021;12(2):152-159.

17. Patil AA, Otto D, Raikar S. Peripheral nerve field stimulation for sacroiliac joint pain. Neuromodulation. 2014;17(1):98-101.

18. Guentchev M, Preuss C, Rink R, Peter L, Sailer MHM, Tuettenberg J. Long-term reduction of sacroiliac joint pain with peripheral nerve stimulation. Oper Neurosurg. 2017;13(5):634-639.
19. Smith AG, Capobianco R, Cher D, et al. Open versus minimally invasive sacroiliac joint fusion: a multi-center comparison of perioperative measures and clinical outcomes. Ann Surg Innov Res. 2013;7 (1): 14 .

20. Kancherla VK, McGowan SM, Audley BN, Sokunbi G, Puccio ST. Patient reported outcomes from sacroiliac joint fusion. Asian Spine J. 2017;11(1):120-126.

21. Schoell K, Buser Z, Jakoi A, et al. Postoperative complications in patients undergoing minimally invasive sacroiliac fusion. Spine J. 2016;16(11):1324-1332.

22. Cross WW, Delbridge A, Hales D, Fielding LC. Minimally invasive sacroiliac joint fusion: 2-year radiographic and clinical outcomes with a principles-based SIJ fusion system. Open Orthop J. 2018;12:7-16.

\section{Publish your work in this journal}

The Journal of Pain Research is an international, peer reviewed, open access, online journal that welcomes laboratory and clinical findings in the fields of pain research and the prevention and management of pain. Original research, reviews, symposium reports, hypothesis formation and commentaries are all considered for publication. The manuscript management system is completely online and includes a very quick and fair peer-review system, which is all easy to use. Visit http:// www.dovepress.com/testimonials.php to read real quotes from published authors. 